bodies-as natives either proved resistant to conversion or rebelled, as they did under Tupac Amaru I in 1570. The result was an image of unconverted natives as disloyal by nature, justifying their subjugation and enslavement. At the same time, Catholic indigenous people often shared Spanish anxiety over Islam, as seen when some of them reported a sighting of a Turkish fleet off the Pacific coast, for which no corroborating evidence could be found. Cook provides a simple explanation in that since the incident occurred shortly after the government mandated celebrations of the victory of Lepanto against the Ottoman fleet, the native population had clearly been influenced by such ritualized propaganda.

Cook concludes that purity of blood became aligned with prejudices over skin colour, and that these were increasingly used as determinants of public reputation and morality in New Spain. Her carefully constructed argument is convincing, her prose clear, and her examples intriguing. The book has high production values, with useful maps, a thorough index, bibliography, and glossary of terms. It is a must read for anyone interested in religious beliefs and interaction in the early modern world.

GARY K. WAITE

University of New Brunswick

\title{
Eggert, Katherine.
}

Disknowledge: Literature, Alchemy, and the End of Humanism in Renaissance England.

Philadelphia: University of Pennsylvania Press, 2015. Pp. 351. ISBN 978-08122-4751-0 (hardcover) \$55.

The decline of humanism created both an epistemological crisis and a crisis of representation. As confidence waned in the promise of some of humanism's guiding assumptions-about the interpretive authority of ancient sources, the preeminence of rhetoric, and the possibility of enumerating and synthesizing all human, natural, and metaphysical knowledge-readers and writers were faced with two discrete but related problems. First, in the absence of a theory of inquiry that might replace humanist thought, scholars, theologians, and poets were forced to continue to rely on the intellectual resources of humanism, even 
though these resources were implicated in erroneous modes of understanding. Second, early modern writers needed to develop a vocabulary that would enable them to negotiate the gap between the usefulness of humanism as a familiar framework for conceptualizing knowledge and its insufficiency as an instrument for advancing that knowledge. Katherine Eggert refers to the system of practices and assumptions that evolved in response to these two problems as "disknowledge," which she describes as a "subspecies of strategic ignorance" (42), and her book explores the evolution of disknowledge in English writing over the course of the late sixteenth and seventeenth centuries. For Eggert, alchemy, with its text-based history and commitment to the significance of linguistic profusion, offered an especially apt reservoir of terms and symbols for the discourse of disknowledge in late humanism. Alchemy becomes, for late humanism generally and for literature in particular, a parallel or shadow discipline, one that serves less to open new fields of inquiry than to insist upon the preeminence of existing forms of knowledge, even while recognizing tacitly that those forms have outlived their usefulness.

To illustrate the operation of disknowledge within the intellectual and literary culture of late humanism, Eggert structures her analysis around four practices associated with disknowledge: forgetting, skimming, avoiding, and fictionalizing. Her chapter on skimming concentrates on the absorption into alchemical and humanist discourse of Kabbalah, the Jewish tradition of esoteric scriptural interpretation. While alchemy provided a vocabulary that enabled scholars to transmute aspects of Kabbalah into a system of Christian mysticism, the conceptual advantages it provided were aided in practice by the strategically simplistic reading of Hebrew texts. Skimming in this way allowed for the articulation of a Christianized Kabbalah, one characterized simultaneously by a superficial appearance of scholarly rigour and by a lack of any genuine engagement with its authentic cultural origins.

Other forms of evasion were even more pronounced. In her chapter on human reproduction, Eggert examines the way in which challenges to the Aristotelian and Galenic model were deliberately brushed aside by humanist scholars anxious about the wider implications of theories that posited explicitly active roles in generation for women. In discussions of The Faerie Queene and Love's Labors Lost, Eggert shows how the purposeful avoidance of post-Galenic theories of anatomy and physiology influenced literary representations of understandings of reproduction. The peculiar set of relations that links alchemy 
to literature also provides the focus of Eggert's final substantive chapter. In discussions of Hamlet, The Alchemist, and The Blazing World, Eggert uses this link to trace the intellectual scope of humanism as it narrows gradually over the course of the seventeenth century. This development is evident in the ways in which Shakespeare, Jonson, and Cavendish incorporate alchemical imagery and vocabulary, which within the specific parameters of fiction are newly established as sources of interpretive gravity rather than objects of skepticism.

Eggert's chapter on forgetting and transubstantiation makes what is likely the book's most significant analytical contribution to the contemporary conversation about early modern knowledge practices. She argues that the Protestant disavowal of transubstantiation as a model for what occurs during the consecration of the host produced important consequences for matter theory more generally. A significant strand of pre-and post-Reformation criticisms of the doctrine drew attention precisely to the inadequacy of Aristotelian physics as a source of analytical vocabulary for conceptualizing the nature of the transformation, both in essence and in quantity. This critical history of transubstantiation as a problem of physics is extremely valuable, though the book may overstate somewhat the centrality of this problem to the broader discourse on the doctrine. Additionally, there are moments at which the chapter appears to conflate the doctrine of transubstantiation with that of the Real Presence, and it makes the puzzling claim that the 1559 Book of Common Prayer leaves open the possibility that the moment of consecration in the Elizabethan church might operate according to a process of transubstantiation. However, because Eggert's primary interest is not doctrine but the theory of matter, the questions that might be raised about this chapter do not seriously affect the overall success of the argument, nor, particularly, of its analysis of the relationship between alchemy and transubstantiation in the poetry of Donne, Herbert, and Vaughan.

Eggert characterizes her book as contributing to ongoing attempts to construct an approach to "historical epistemology" (7), and her framing of disknowledge outlines very effectively a series of theories and practices that early modern readers and writers adopted in response to the growing awareness of the insufficiencies of humanist thought. As such, we might ask whether Disknowledge might usefully have extended its conceptual reach from memory, rhetoric, and what we now call science into practical and abstract philosophies favoured by late humanist thinkers. Neostoicism in particular suggests itself 
as a complementary knowledge system, and the book may have benefitted from some engagement with Angus Fletcher's work on the concept of "partial belief." But to indicate ways in which the book's framework might be applied elsewhere is less to offer criticism than to identify the remarkable strength of the argument and its overall utility. This is a thorough, imaginative, and timely study that suggests multiple possibilities for further inquiry, and we in the field are extremely fortunate to have it.

DAN BREEN

Ithaca College

\section{Eire, Carlos M. N.}

\section{Reformations: The Early Modern World, 1450-1650.}

New Haven, CT: Yale University Press, 2016. Pp. xviii, 893 + ill. ISBN 978-0300-11192-7 (hardcover) US $\$ 40$.

Carlos Eire is a seasoned historian of the Reformation whose early works on iconoclasm and on death have been standards of the Reformation reading list for decades. In recent years, he has adopted the posture of the outsider, an interpreter out of step with the dominant historiographical consensus, and quite unapologetically so. This makes his nearly one thousand page contribution to the current anniversary-driven Reformationsindustrie all the more interesting. Where does a self-proclaimed iconoclast really fit among the historians of various orientations and ideologies who are shuffling to make space for themselves on a very crowded path?

Some historians fall out of step because they are running ahead of the crowd, while others do so because they are dragging their feet. Eire may be closer to the latter. For all the bulk of his book, its framing of the Reformation works quite unambiguously with categories of "Protestant" vs "Catholic" that are fixed, distinct, and traditional. To achieve this, Calvinism and Radicalism define much of what is described as generic "Protestantism," while "Catholicism" is viewed through the Tridentine telescope, though sometimes from the wrong end, so that much of fifteenth-century Catholicism becomes a miniaturized version of its seventeenth-century successor. The varieties within Protestantism are duly acknowledged though less often internalized. The strongly lay elements 